\section{Mimicry and viceroy butterflies}

SIR - Ritland and Brower ${ }^{1}$ reassess defensive mimicry among monarch, queen and viceroy butterflies in Florida (see Scientific Correspondence 351, 611-612; 20 June 1991). These three butterfly species have complex population fluctuations in both space and time in north Florida. The monarch, a longdistance migrant, is present in spring, breeding from April to June, and again on passage to overwintering locations during October and November ${ }^{2}$. The experimental monarchs were collected in autumn, during their migration, at a time when their chemical defences are almost at their lowest effectiveness. By contrast, first-generation monarchs in spring have very high chemical defences and would produce predator responses much more like those described by J. V. Z. Brower ${ }^{3}$, or by Platt et $a l{ }^{4}$, rather than those reported by Ritland and L. Brower $^{1}$. This means that the spatial and temporal dynamics of monarch, viceroy and queen populations need to be assessed in relation to the dynamics and behaviour of predator populations.

How can we reach conclusions about the ecological operation of mimicry without understanding the diversity of potential natural enemies that might select for mimetic defences ${ }^{5}$ ? We need to assess which are the relevant natural enemies and then demonstrate how populations of models, mimics and natural enemies interact behaviourally, temporally and spatially and how their numbers change according to relative frequencies of interaction.

Moreover, Ritland and Brower studied butterflies at a well-known viceroy hybrid zone in Florida, which makes their conclusions even more difficult to accept. Even without these added changes in frequencies of different mimetic phenotypes, mimicry is complicated. The demonstration of unacceptability to one predator species is only one very small part of unravelling the dynamics of interacting populations of prey and predator complexes towards an understanding of mimicry.

STEPHEN MALCOLM

Department of Biology, Imperial College, Silwood Park, Ascot, Berkshire SL5 7PY, UK

1. Ritland, D. B \& Brower, L. P. Nature 350, 497-498 (1991).

2. Malcolm, S. B. \& Brower, L. P. Experientia 45, 284-295 (1989).

3. Brower, J. V. Z. Evolution 12, 32-47; 273-285 (1958).

4. Platt, A. P. Coppinger, R. P. \& Brower, L. P. Evolution 25, 692-701 (1971)

5. Malcolm, S. B. Trends ecol. Evol. 5. 57-62 (1990)

SIR - Guilford ${ }^{1}$ questions whether our experiment $^{2}$ really demonstrates that viceroys are unpalatable, suggesting instead that they could have been "gustatory mimics" of monarchs that the birds previously tasted during the experiment. This interpretation is excluded because the six birds that received viceroys before monarchs or queens (birds A-F) showed aversions similar to the 10 birds that received viceroys after monarchs or queens (birds G-P in our Table 1$)^{2,3}$. Moreover, birds that found viceroys unpalatable did not necessarily treat monarchs or queens as unpalatable, and vice versa; no correlation existed either between the percentages of monarchs and viceroys eaten by individual birds, or between their rejection behaviours towards the two species ${ }^{3}$. These facts similarly exclude Guilford's interesting suggestion of pyrazine-based olfactory mimicry.

We agree with Malcolm's comment (above) on the spatiotemporal variation in monarch chemical defence, but this does not vitiate our finding that Florida viceroys are themselves unpalatable to an avian predator, with the attendant implications for mimicry theory. In addition, because we focused on palatability by feeding only abdomens to the birds, Malcolm's criticism that our viceroys were collected in a transition zone of wing colour phenotype seems irrelevant; the criticism also does not gain support from other data ${ }^{3-5}$, indicating that viceroys outside the transition zone are also unpalatable.

DAVID B. RITLAND LINCOLN P. BROWER

Department of Zoology,

University of Florida,

Gainesville, Florida 32611, USA

1. Guilford, T. Nature 351, 611 (1991)

2. Ritland, D. B. \& Brower, L. P. Nature 350, 497-498 (1991).

3. Ritland, D. B. thesis (University of Florida, Gainesville, 1991).

4. Brower, J. V. Z. Evolution 12, 32-47; 273-285 (1958) . Platt, A. P., Coppinger, R. P. \& Brower, L. P. Evolution 25 692-701 (1971).

SIR - In the light of the seminal research done on the viceroy butterfly by D. B. Ritland and L. P. Brower (Nature 350, 497-498; 1991) we have set up a group whose aim is to restore the proper place of this species in the scientific community and popular press. Obviously the viceroy should no longer be relegated to a vice-regal position with respect to the monarch. A committee will search for an appropriate common name, if one can use the term 'common' when referring to things regal. A number of suggestions have been made sovereign, imperator, suzarain, emperor. Those with computer backgrounds thought that Viceroy Plus (or Viceroy + ) would be appropriate, but others, concerned about the political future of Canada, thought that perhaps using the French world for monarch (monarque) would be better. There was then concern about what each butterfly would be called in French translations, which are standard in Canada.

Our committee estimates that it will cost about Canadian $\$ 10,000$ to send a representative to the Nomenclature Committee of the World Lepidopteran Congress. To this end the local UP THE VICEROY committee will attempt to raise most of this through the sale of buttons, posters and T-shirts. The hottest selling money-maker is the UP THE VICEROY T-shirt, with two viceroys in the Fighting $U p$ position. Any readers sharing our concern should send contributions to our treasurer, Dan Sarki, at our office in Thunder Bay.

WAYNe MACCALLUM BRUCE THACKER GORD JOHNSON

Lake Superior Fisheries Unit,

PO Box 5000,

Thunder bay, Ontario,

P7C 5G6, Canada

\section{Oil spill clean-up}

SIR - On 24 March 1989, approximately 11 million gallons of crude oil spilled into the waters of Prince William Sound, Alaska, eventually contaminating nearly 1,000 miles of shoreline ${ }^{1}$. Because of the apparent success of bioremediation on this oil spill, and the consideration of this technology for other oil spills ${ }^{2}$, we have investigated the effect of bioremediation on ecology and human health.

To determine whether bioremediation would be effective, the US Environmental Protection Agency (EPA) conducted a large field demonstration project to evaluate the use of fertilizers for accelerating natural biodegradation of spilled oil by indigenous microorganisms ${ }^{1}$. Both a slow-release, watersoluble fertilizer and an oleophilic formulation were used for the treatment of the beaches.

During biodegradation, the toxicity of the polluting material may increase when non-toxic constituents are converted to toxic species. Toxic compounds refractory to biological degradation may further compromise the effectiveness of the treatment technique. In such complex situations, it is impractical to use analytical chemistry to detect and quantify all toxins that have the potential to cause chronic effects. Consequently, biological test systems complement chemicalspecific analyses. Because carcinogenic and mutagenic effects are of interest both to environmental and to health scientists, the EPA bioremediation efforts were monitored with the spiral Salmonella/mammalian microsome mutagenicity assay ${ }^{3}$. The Salmonella assay has been used to demonstrate the mutagenicity of crude oils, including 